\title{
Promoter-specific Methylation Profile
}

National Cancer Institute

\section{Source}

National Cancer Institute. Promoter-specific Methylation Profile. NCI Thesaurus. Code C129890.

The analysis of all of the methylation of all promoter sequences in the genome in a biological sample 